\title{
Design ativismo ou design ativista?
}

\section{Design activism or activist design?}

\author{
Gheysa Caroline Prado, Universidade Federal do Paraná.
} gheysa.prado@ufpr.br

\section{Resumo}

Este artigo tem como objetivo discutir as terminologias de uma área de atuação do design, design ativista ou design ativismo, buscando estabelecer uma recomendação de sua utilização em português. Este campo questiona o status quo em suas práticas, com a intenção de influenciar políticas públicas e práticas culturais em prol de sociedades mais equânimes. Para tal, foi realizada uma revisão de literatura narrativa em textos canônicos do design que em algum ponto questionam sua forma de atuação usual, em autores e autoras precursores do uso destes termos em âmbito global e local para compreender as diferenças entre eles. Também foi realizada revisão bibliográfica sistemática para identificar a aplicação corrente dos termos nas publicações existentes. Os resultados apontam para uma prevalência do termo design acivism nas publicações de língua inglesa e design ativista naquelas em português. A partir da análise dos achados e das discussões, recomenda-se a adoção do termo design ativismo por este abranger melhor suas práticas de uso e significados.

Palavras-chave: design ativista, design ativismo, design social, design, política.

\begin{abstract}
This paper aims to discuss terminologies from a design field area, activist design or design activism, trying to stablish a recommendation for its use in Portuguese. This field area confronts the status quo in its practices, intending to influence public policies and cultural practices to reach fairer societies. To that, the author conducted a narrative literature review in canonical design texts which at some point confront the usual design practices and in the pioneer authors who used these terms worldwide and locally to understand the difference among them. A systematic literature review was also part of the research strategy to identify the prevailing use of the terms at the existent published works. The results point out that the term design activism is prevalent in English publications and activist design is used in the Portuguese ones. Based on the findings and discussions, the author recommends the use of the term design activism also in Portuguese, since it covers better its usage practices and meanings.
\end{abstract}

Keywords: activist design, design activism, social design, design, politics. 


\section{Introdução}

A atividade de design, em suas origens, é destinada a solucionar problemas pontuais, com foco em aspectos produtivos dos artefatos e cujo objetivo, no âmbito das sociedades capitalistas, é gerar lucro (FORTY, 2007). Não possui, na maioria das vezes, visão de longo prazo sobre suas consequências (obsolescência, descarte etc.) (PAPANEK, 1973; DORMER, 1990). No entanto, já há algum tempo e por uma série de pressões internas e externas, este campo do conhecimento vem buscando contribuir para o desenvolvimento sustentável direcionando esforços na promoção dos pilares ambiental, social e econômico da sustentabilidade. Por se tratar de um tripé, é indispensável que estejam em equilíbrio e contemplados de forma equivalente e indissociável. Neste sentido, vimos o surgimento de várias frentes e abordagens como o eco design, design sustentável, design social, design para inovação social, design para o consumo e comportamento sustentáveis entre outras. Ainda assim, devido ao fato de o crescimento econômico ser o maior balizador e princípio central de organização da sociedade capitalista, a dimensão econômica segue privilegiada sobre as demais (FUAD-LUKE, 2009). Face a esta perspectiva, os problemas ambientais e sociais decorrentes deste modelo são seus próprios custos (THORPE, 2012), levando a uma crise do próprio conceito de desenvolvimento sustentável (FUAD-LUKE, 2009).

Esta crise se deve, sobretudo, à dificuldade de enfrentamento e confronto com o sistema econômico vigente e joga, muitas vezes, a responsabilidade pelas escolhas e suas consequências exclusivamente no indivíduo, enquanto usuário final. Nesta lacuna, surge uma abordagem ativista do design, focando a atuação onde a lógica capitalista falha, contestando o status quo nas áreas sociais, ambientais, econômicas e políticas, buscando formas de diluição do poder ${ }^{1}$ e estratégias de participação política da sociedade nas esferas públicas de decisão, para além dos processos eleitorais. Esta abordagem direcionada ao ativismo busca por modelos alternativos da prática do design e tem potencial para promover mudanças sociais por meio do engajamento político construtivo, do questionamento, contestação e, até mesmo, de uma eventual ruptura nos processos internos e externos convencionados, criando e propondo contra narrativas (FUAD-LUKE, 2009; THORPE, 2012; MARKUSSEN, 2013, JULIER, 2013). Julier (2013) afirma ainda que o design ativismo é um movimento mais autoconsciente e responsivo a circunstâncias, que implica intenção e entusiasmo para agir em determinadas situações.

O uso de termos específicos para se referir a essa abordagem, no entanto, é bastante recente (Julier, 2013) e mais recente ainda em língua portuguesa, na qual não há um consenso quanto à sua utilização. Assim, este artigo tem como objetivo discutir as terminologias desta área de atuação do design - design ativista ou design ativismo - buscando estabelecer uma recomendação de sua utilização em português. Para tal, foi realizada revisão de literatura narrativa em textos canônicos do design que levantam e apresentam reflexões sobre o papel social do design e de designers, e em autores e autoras precursores do uso destes termos em âmbito global e local para compreender as diferenças entre eles. Além disso, também foi realizada revisão bibliográfica sistemática de modo a identificar a aplicação corrente dos termos nas publicações existentes. Os

\footnotetext{
1 "poder que domina os seres humanos e o ser "homem" sem dominar nenhuma das forças que saem deles e se voltam contra eles: nem a técnica, nem a demografia, nem o espaço! (...) esse poder abstrato que passa por utilizar meios objetivando um fim desconhecido, ao passo que se converteu em seu próprio fim." (LEFEBVRE, 2016 p.23)
} 
resultados apontam para uma prevalência do termo design activism nas publicações de língua inglesa e design ativista naquelas em português. A partir da análise dos achados e das discussões, recomenda-se a adoção do termo design ativismo para o português por este abranger melhor suas práticas de uso e significados.

\section{Procedimentos metodológicos}

Buscando estabelecer uma recomendação de utilização de um termo para a abordagem ativista do design em português, foi realizada revisão de literatura narrativa em textos canônicos do design que levantam e apresentam reflexões sobre o papel do design e de designers na sociedade. Além disso, buscou-se também analisar autoras e autores precursores do uso destes termos em âmbito global e local com o objetivo de compreender as principais diferenças entre eles. Também foi realizada revisão bibliográfica sistemática de modo a identificar a aplicação corrente dos termos nas publicações existentes.

Para a revisão narrativa foram utilizados, sempre que possível, os textos das edições traduzidas para o português. Para a análise dos textos de autores e autoras precursores do uso dos termos, especialmente internacionalmente, foram utilizadas publicações periódicas revisadas por pares e os livros publicados.

Já para a revisão bibliográfica sistemática (RBS), cuja função principal neste artigo foi a identificação da aplicação corrente dos termos nas publicações e suas variações, foram seguidas as recomendações de Dresch, Lacerda e Antunes Jr. (2015). Assim, foi adotada como estratégia de revisão, a revisão configurativa, de caráter mais exploratório e buscando, a partir da interpretação dos estudos encontrados, explorar a teoria utilizando o método indutivo e propondo uma "renderização teórica coerente" (DRESCH, LACERDA E ANTUNES JR., 2015. p.147).

Inicialmente, não foi incluído recorte temporal e tal abordagem se mostrou apropriada, pois não foram encontrados artigos e outras publicações com os termos pesquisados antes do ano 2000 e apenas 5 publicações antes de 2010. As fontes de busca utilizadas para a RBS foram as bases de dados Portal Periódico CAPES e Scopus para os termos em inglês "design activist", "activist design" e "design activism" e português "design ativista" e "design ativismo". Tendo em vista que a busca inicial nas bases apresentadas não retornou resultados para os termos em português, ampliou-se a busca de "design ativista" e "design ativismo" para a internet com o uso do Google Scholar conforme configurações de busca apresentadas no quadro 1. 


\begin{tabular}{|l|l|l|l|l|}
\hline Fonte de busca & Termos pesquisado & Idiomas & $1^{\circ}$. filtro & $2^{\circ}$. filtro \\
\hline $\begin{array}{l}\text { Portal Periódico } \\
\text { CAPES }\end{array}$ & $\begin{array}{l}\text { "design activist" } \\
\text { "design activism" } \\
\text { "activist design" } \\
\text { "design ativismo" } \\
\text { "design ativista" }\end{array}$ & $\begin{array}{l}\text { Inglês e } \\
\text { português } \\
\text { pcop pares }\end{array}$ & $\begin{array}{l}\text { Periódicos revisados } \\
\text { por }\end{array}$ & $\begin{array}{l}\text { Tipo de recurso: } \\
\text { artigo }\end{array}$ \\
\hline $\begin{array}{l}\text { "design activist" } \\
\text { "design activism" } \\
\text { "activist design" } \\
\text { "design ativismo" } \\
\text { "design ativista" }\end{array}$ & $\begin{array}{l}\text { Inglês e } \\
\text { português }\end{array}$ & Artigo & - \\
\hline Google Scholar & $\begin{array}{l}\text { "design ativista" } \\
\text { "design ativismo" }\end{array}$ & Português & Trabalhos acadêmicos & - \\
\hline \multicolumn{7}{|c|}{ Quadro 1: Panorama do procedimento para RBS } & \\
\hline
\end{tabular}

Posteriormente, os resultados encontrados foram tabulados identificando as seguintes informações: fonte de busca, termo(s) por meio do qual o material foi localizado, idioma, tipo de publicação, título, autores, local de publicação (periódico, evento etc.), ano, e resumo. Esta tabulação permitiu a consolidação dos dados, a eliminação de títulos repetidos em buscas distintas, e a identificação de títulos encontrados que fizeram uso de dois ou três termos simultaneamente. Também foi utilizado como critério de exclusão a ou as áreas temáticas que desviassem do campo amplo do que é entendido por design como atividade projetual, que engloba o próprio design, arquitetura, engenharia etc. Por fim, a partir da leitura dos resumos, foram selecionados os materiais que seriam lidos na íntegra tendo em vista o objetivo do presente artigo, de refletir e discutir as terminologias mencionadas.

Na próxima seção, são apresentados e discutidos os resultados da revisão bibliográfica narrativa, apresentando um panorama do design como prática ativista. Na sequência, são analisadas as definições léxicas dos termos ativismo, ativista e seus sufixos -ismo e -ista e, a partir da costura feita com os resultados das revisões bibliográficas, narrativa e sistemática, discutemse os achados das diferentes terminologias adotadas em inglês e em português, estabelecendo uma recomendação de termo a ser utilizado em português.

\section{Design como prática ativista}

A prática do design - de criar e produzir artefatos, considerar uma situação, vislumbrar melhorias e agir para colocá-las em prática - antecede a profissão e é parte do que nos faz humanos (FRIEDMAN, 2000). Ainda assim, pode-se dizer que um marco do design, enquanto área do conhecimento, ou ao menos da utilização corrente do termo designer, enquanto profissão, é do início do século XIX, ligado à Revolução Industrial, com um processo mais contundente de separação entre o projetar e o fabricar. Antes disso, a partir do século XVI, na Inglaterra, no período do Renacimento, a palavra disegno era utilizada com a ideia de desenhar ou rascunhar com a noção de planejar algo ligado às artes, em 1548 a primeira citação da palavra design como verbo, em inglês, é feita no dicionário Merriam-Webster onde também, em 1588 é apresentada como substantivo. No século XVII, havia registro da palavra designer no Oxford English Dictionary (HAUFFE, 1998; DENIS, 2000, FRIEDMAN, 2000). 
O design é, antes de tudo um processo de pensamento e planejamento (FRIEDMAN, 2000). atualmente definido como processo estratégico de solução de problemas promotor de inovação, sucesso comercial, e que leva a uma melhor qualidade de vida por meio de produtos, sistemas, serviços e experiências (WDO, 2015) é, na verdade, mais que isso. Um dos precursores da discussão, Simon (1996, p.114, tradução nossa), afirma que o design "está preocupado como as coisas deveriam ser" e desenvolve os artefatos para atingir estes objetivos, destinados a transformar situações existentes em outras preferíveis. Por meio dos seus artefatos, o design dá "formas tangíveis e permanentes às ideias sobre quem somos e como devemos nos comportar" (FORTY, 2007 p.12), já que, segundo Buchanan (1992, p.8, tradução nossa) "não há nenhuma área da vida contemporânea na qual o design (...) não desempenhe um fator significativo em moldar a experiência humana". No entanto, na maioria das vezes, estes artefatos reforçam o paradigma dominante já que são "um reflexo de nossos sistemas econômicos (...) e de valores emocionais e culturais" (SUDJIC, 2010 p.49). Nesta mesma direção, Fuad-Luke (2009 p.36, tradução nossa) aponta que os artefatos produzidos são "representações que vivem dentro das culturas, informam identidades e relações sociais e geram feedback para a próxima geração de produção".

Essa lógica, que naturaliza a criação e as mudanças nos artefatos como se fossem uma evolução natural e progressiva, ignora o fato de que tais mudanças são impulsionadas "pelas pessoas e as indústrias que os fazem e pelas relações entre essas pessoas e indústrias e a sociedade em que os produtos serão vendidos." Além disso, "a história do design é também a história das sociedades: qualquer explicação da mudança deve apoiar-se em uma compreensão de como o design afeta os processos das economias modernas e é afetado por eles.” (FORTY, 2007 p.14)

Assim, ainda que boa parte dos estudos da história do design não deixem claras estas ligações, Fuad-Luke (2009) apresenta um levantamento identificando ações e movimentos de design e designers, ao longo da história, que se entendiam de alguma forma responsáveis por se posicionar ativamente como contra narrativas ao paradigma dominante, criando pressões, promovendo mudanças e, efetivamente, beneficiando determinados grupos invisibilizados pelo status quo.

Fuad Luke (2009) aponta que os primeiros indícios destas ações e movimentos, nos quais é possível identificar práticas ativistas, são tão antigos quanto a própria profissão e aparecem em meados do século XVIII, com o estabelecimento, na Inglaterra, da primeira empresa de cerâmica de mesa a fazer uso da produção em massa, que produzia jogos de jantar bonitos e financeiramente acessíveis, antes privilégio apenas das elites. No século seguinte, essa movimentação fica ainda mais evidente. Na Grande Exibição de 1851, no Palácio de Cristal em Londres, críticas de John Ruskin e Augustus Pugin à ornamentação grosseira e à baixa qualidade dos produtos industriais os colocam como primeiros ativistas do design. Não muito tempo depois, em 1861, com a Morris, Marshall \& Faulker \& Co, William Morris busca promover a simplicidade vernacular revitalizada, com a perícia e a habilidade dos trabalhos artesanais como forma de agenciar coesão social, ainda que não tenha atingido seu objetivo. Estes personagens foram, posteriormente, apontados como os precursores do movimento britânico de Artes e Ofícios que, pode-se dizer, foi o primeiro movimento reformista do design, buscando contribuir para mudanças sociais positivas por meio de seus artefatos e propondo contra narrativas. 
Algumas décadas depois ao Artes e Ofícios, a Deutscher Werkbund já não se opunha aos processos industriais e à manufatura, mas tinha, tal qual Morris, aspirações sociais como imperativas. Fundada em 1907, seu foco era atingir o bom design, com características funcionalistas. A ideia radical, apresentada pelo grupo, que tinha entre seus integrantes Walter Gropius e Mies Van der Rohe, foi a de que os interiores domésticos compostos pela mobília, iluminação e a configuração do espaço como um todo, "poderia elevar a qualidade de vida de seus habitantes" (FUAD-LUKE, 2009 p. 38). As ideias iam para além das configurações formais das construções e produtos, seus membros tinham ambições socialistas e acreditavam que, por meio de suas criações, seria possível superar conflitos de classes.

O ponto de que a "ênfase na contra narrativa é importante pois sugere que de alguma forma é diferente da narrativa principal (...) dando voz a outras possibilidades (...) elicitando mudanças e transformações sociais" (FUAD-LUKE, 2009 p.27), ainda que central na tentativa de estabelecer uma definição a estas práticas ativistas, deixa uma lacuna do ponto de vista político. Para Thorpe (2012), não é possível pensar em transformação social sem confrontar o fato de que o sistema econômico vigente é parte do problema e que o impacto e a influência do design necessitam chegar à esfera política, por meio de políticas públicas com foco nas práticas cotidianas. Além disso, para além da política como resultado das práticas de design, é preciso reflexão sobre o aspecto político relativo à metodologia do próprio design, entendendo seus dispositivos internos em seus processos de produção (PORTINARI e NOGUEIRA, 2016), evitando assim a mera reprodução do paradigma dominante com uma nova terminologia.

É crucial, neste momento, apontar que as contra narrativas propostas, apontadas acima, por seu desejo aparentemente genuíno de transformação social, parecem buscar se descolar, de alguma forma, da ideia da produção de mitos ${ }^{2}$, conforme apresentada por Forty (2007). Isto porque, por meio dos seus artefatos, "o design tem a capacidade de moldar os mitos numa forma sólida, tangível e duradoura, de tal modo que parecem ser a própria realidade" (FORTY, 2007 p.15).

A realidade, no entanto, segundo Bonsiepe (1983) depende do enfoque. Segundo o autor, quando este vem do centro, o "desenho (design) é um processo de transformar sonhos em realidade" (KOBERG e BAGNALL, 1972 apud BONSIEPE, 1983 p.67). Já quando o enfoque vem da periferia, o "desenho (design) é um processo de transformar a realidade em um sonho".

Ainda que as ações ativistas tenham seguido acontecendo, na prática cotidiana do design os temas sociais e ambientais eram bastante insipientes, quando a partir de meados da década de 1960, abrem-se caminhos para esta forma de atuação social e política mais ampla, conforme explicitado por Resnick (2019), em um levantamento específico sobre a definição do designer socialmente responsável. Nesta trajetória, na década de 1970, Papanek (1973) fez uma profunda reflexão e crítica acerca do tema, apontando que a habilidade dos designers de solucionar problemas é, muitas vezes, desviada ao ser contratados para criar problemas cuja solução está na

\footnotetext{
2 Ideias expressas sobre o mundo. No caso do design, seus produtos (móveis, materiais gráficos etc.) representam conceitos sobre o que se quer que seja pensado sobre determinado ambiente ou situação. Exemplo: “(...) mito de que o trabalho no escritório é divertido, sociável e excitante” é sustentado e ganha credibilidade pelo design do "mobiliário moderno em cores vivas e formas levemente alegres" (FORTY, 2007 p.15-16).
} 
invenção e produção de produtos desnecessários. Na mesma época Ritter e Webber (1973) desenvolvem a teoria de que problemas sociais e ambientais são wicked problems que, entre outras características, possuem alto nível de complexidade, são sintomas de outros problemas, possuem mais de uma explicação possível e cujas soluções não são definitivas.

Nesta direção, Cross (1982) discute as bases teóricas para o estabelecimento do design como um campo do conhecimento coerente, que tanto do ponto de vista da pesquisa, quanto de formação de novos profissionais, é capaz de lidar com os wicked problems, de maneira construtiva. Também apoiado na teoria de Rittel e Webber (1973), no início dos anos 1990, Buchanan (1992) aponta o crescimento da atuação dos designers, nas décadas de 1970 e 1980, em áreas relacionadas a aspectos sociais e ambientais complexos, sendo responsáveis por levantar novas questões, ideias relevantes e propor formas de abordagem distintas para lidar com os problemas contemporâneos. Neste sentido, Margolin e Margolin (2002) propõem um modelo social da prática do design, na qual a principal intenção é atender as necessidades humanas. Manzini (2008 p.16), por sua vez, aponta como os designers podem ser, de fato, parte da solução, uma vez que são atores sociais, lidando "com as interações cotidianas dos seres humanos e seus artefatos" e, como tal, tem a capacidade de propor cenários de bem-estar para "visões compartilhadas sobre futuros possíveis", promovendo o que o autor chama de inovação social.

Com um texto menos veemente, Munari (2015) apresenta diversas áreas e grupos de pessoas nas quais é possível encontrar o que ele chama de "problemas de design", afirmando que estes problemas são identificados a partir das necessidades humanas, e cuja solução oferece melhoria na qualidade de vida. Na mesma direção de Papanek, aponta que "frequentemente (...) a indústria tende a inventar falsas necessidades para poder produzir e vender novos produtos. Nesse caso, o designer não deve deixar-se envolver numa operação que se destina ao lucro exclusivo do industrial e ao prejuízo do consumidor.” (MUNARI, 2015 p.30).

Do mesmo modo, Löbach (2001 p.14), ao definir design como "o processo de adaptação do ambiente 'artificial' às necessidades físicas e psíquicas dos homens na sociedade" sinaliza que o designer pode ter esse papel de protetor, e que essa seria a postura desejável. No entanto, deixa claro que as pressões econômicas frequentemente impactam no cumprimento desta tarefa, ocasionando efeitos negativos. Destaca, dentre estes efeitos, principalmente os ambientais, ainda que mencione, posteriormente, que a necessidade de questionamento acerca da importância e impactos sociais dos projetos antes do início de seu desenvolvimento, não é apenas de designers, mas antes, de seus contratantes. Isto, claro, na lógica, apresentada por Dormer (1990 p. 36) em que "o designer só entra em ação quando seus serviços são requisitados".

Assim, Sudjic (2010 p.24) contrapõe essas visões apontando uma "evolução do designer como profissional" destacando que designers deixaram de se considerar e se apresentar como reformadores sociais e idealistas, como William Morris em meados do século XIX e a Deutscher Werkbund no início do século XX, para em alguma medida "se tornarem carismáticos vendedores de panaceias comandados por Raymond Loewy nos Estados Unidos de meados do século XX". E, nesta reflexão de pensar se os designers passam a ser meramente tecnocratas direcionando suas habilidades à melhor oferta financeira ou se há propósitos sociais e ambientais (HESKETT, 1997), Sudjic (2010 p.24) aponta que "mais ou menos no meio dessas duas versões de design está a ideia de que o design é um serviço público". 


\section{$O$ ativismo no design e o design ativismo}

Ainda que o objetivo da seção anterior não tenha sido esgotar o mapeamento das práticas ativistas no design, é possível perceber, a partir do apresentado, que tais ações não são recentes. Já a consolidação do conhecimento e suas classificações como sendo ativistas é, o que justifica o fato de não haver consenso sobre o uso de uma terminologia específica para a prática. Ainda assim, com base em alguns dos autores precursores do uso dos termos, e considerando a capacidade do design de impactar e ser impactado pelo seu entorno, serão apresentadas algumas das definições que vem sendo utilizadas.

Fuadluke (2009 p.27, tradução nossa) define design activism como "o pensamento, a imaginação e a prática de design aplicada de forma intencional ou não intencional para criar uma contra narrativa direcionada a gerar e balancear positivamente mudanças sociais, institucionais, ambientais e/ou econômicas”. Já Thorpe (2012) aponta que design activism é uma forma de atuar politicamente, de maneira engajada, com o objetivo de confrontar o sistema econômico vigente influenciando práticas de consumo. Nessa mesma direção, Julier (2013) entende o design activism como um movimento que contesta o neoliberalismo e busca por modelos de práticas alternativas. Outros termos encontrados, design activist e activist design são entendidos pelos autores Fuadluke (2009) e Thorpe (2012) como o profissional designer atuante neste campo e a prática na área, respectivamente.

Assim, a Revisão Bibliográfica Sistemática realizada segundo as recomendações de Dresch, Lacerda e Antunes Jr. (2015) utilizou como strings de busca os termos "design activism", "design activist", "activist design", "design ativismo" e "design ativista", separadamente e sem o uso de operadores boleanos. Tal como apresentado nos procedimentos metodológicos, todos os termos foram utilizados nas bases de dados e, devido à não obtenção de resultados para os termos em português nestas fontes, ampliou-se a busca deles para o Google Scholar.

Após a aplicação dos filtros e critérios de exclusão indicados o quadro 2 contêm a síntese dos resultados encontrados para os dois idiomas pesquisados, antes da leitura dos resumos.

\begin{tabular}{|c|c|c|c|c|}
\hline $\begin{array}{l}\text { Idioma / } \\
\text { Fonte de busca }\end{array}$ & Termos & $\begin{array}{l}\mathrm{N}^{0} \cdot \mathrm{de} \\
\text { resultados }\end{array}$ & Período & $\begin{array}{l}\text { Total por } \\
\text { idioma }\end{array}$ \\
\hline \multirow{7}{*}{$\begin{array}{l}\text { Inglês } \\
\text { (Bases de dados) }\end{array}$} & "design activism" & 82 & $2000-2021$ & \multirow{7}{*}{114} \\
\hline & "design activist" & 5 & 2009-2019 & \\
\hline & "activist design" & 19 & $2009-2021$ & \\
\hline & "design activism" e "design activist" & 5 & $2011-2020$ & \\
\hline & "design activism" e "activist design" & 1 & 2013 & \\
\hline & "design activist" e "activist design" & 1 & 2013 & \\
\hline & $\begin{array}{l}\text { "design activism" e "activist design" } \\
\text { e "design activist" }\end{array}$ & 2 & 2014-2017 & \\
\hline \multirow{3}{*}{$\begin{array}{l}\text { Português } \\
\text { (Google Scholar) }\end{array}$} & "design ativismo" & 9 & $2016-2020$ & \multirow{3}{*}{41} \\
\hline & "design ativista" & 29 & $2012-2021$ & \\
\hline & "design ativismo" e "design ativista" & 3 & 2020 & \\
\hline
\end{tabular}

Quadro 2: Resumo do resultado da RBS

Fonte: a autora (2021)

A partir da sumarização dos resultados, foi possível identificar a primeira diferença acerca dos usos dos termos. Em inglês, a maioria dos artigos publicados em periódicos revisados por pares faz uso unicamente do termo 'design activism' (82 de 114), cuja tradução para o português é 
design ativismo. Enquanto o termo 'activist design', cuja tradução literal é 'design ativista' não apareceu como sendo utilizado com tanta frequência (19 de 114 se considerar o uso exclusivo e 23 de 114 quando combinado com os demais termos). No entanto, nas publicações encontradas em português, o termo mais utilizado para se referir a esta forma de atuação do design é design ativista (29 de 41).

Outro aspecto que cabe destacar é quanto ao período das publicações, que em inglês tem início aproximadamente uma década antes das publicações em português e, para além da RBS, já havia ao menos duas publicações de livros consolidadas e citadas neste trabalho - Fuad-Luke (2009) e Thorpe (2012) - até o ano de 2012.

Face a estas diferenças e impasse, e uma vez que o objetivo do presente artigo é exatamente estabelecer uma recomendação de utilização de termo aplicável à língua portuguesa, tendo em vista a insipiência do tema neste cenário, recorreu-se aos significados dos termos isolados, apresentados no quadro 3, conforme definição no dicionário Oxford Languages.

\begin{tabular}{|c|c|}
\hline $\begin{array}{l}\text { ativismo } \\
\text { substantivo masculino } \\
\text { 1. FILOSOFIA } \\
\text { qualquer doutrina ou argumentação que privilegie a } \\
\text { prática efetiva de transformação da realidade em } \\
\text { detrimento da atividade exclusivamente especulativa, } \\
\text { freq. subordinando sua concepção de verdade e de valor } \\
\text { ao sucesso ou pelo menos à possibilidade de êxito na } \\
\text { ação. } \\
\text { 2. LITERATURA } \\
\text { gênero de literatura com conteúdo político; literatura } \\
\text { engajada. } \\
\text { 3. POLÍTICA } \\
\text { (CIÊNCIA•POLÍTICA•IDEOLOGIA) } \\
\text { propaganda a serviço de uma doutrina ideológica, } \\
\text { partidária, sindical etc. } \\
4 \text {. POLÍTICA } \\
\text { (CIÊNCIA•POLÍTICA•IDEOLOGIA) } \\
\text { trabalho desenvolvido esp. em meios } \\
\text { revolucionários, políticos, estudantis, sindicais etc.; } \\
\text { militância. } \\
\text { Origem } \odot \text { ETIM ativo + -ismo }\end{array}$ & $\begin{array}{l}\text { ativista } \\
\text { adjetivo de dois gêneros } \\
\text { 1. relativo a ativismo. } \\
\text { 2. adjetivo e substantivo de dois gêneros } \\
\text { partidário do ativismo. } \\
\text { 3. adjetivo e substantivo de dois gêneros } \\
\text { que ou aquele que trabalha para alguma causa; } \\
\text { defensor, militante. } \\
\text { "a. do movimento negro" } \\
\text { Origem } \\
\text { ○ ETIM ativo + -ista }\end{array}$ \\
\hline $\begin{array}{l}\text {-ismo } \\
\text { sufixo } \\
\text { do gr. -ismós,oû, pelo lat. -ismus,i; em port. designa } \\
\text { intoxicação de um agente (alcoolismo) e movimentos } \\
\text { sociais ou ideológicos (calvinismo, feminismo, } \\
\text { tropicalismo); cumpre notar a relação -ismo : -ista : - } \\
\text { ístico }\end{array}$ & $\begin{array}{l}\text {-ista } \\
\text { sufixo } \\
\text { do suf. gr. -istēs, para designar o praticante de uma } \\
\text { atividade ou o adepto de um movimento ideológico: } \\
\text { oftalmologista, pianista, reformista; }\end{array}$ \\
\hline
\end{tabular}

Assim, a partir do ponto de vista morfológico, percebe-se inicialmente a diferença com relação à classe das palavras. Ativismo, por ser substantivo, tem como característica designar ou nomear determinada coisa ou atividade. Já ativista, enquanto adjetivo, tem a função de indicar atributo, qualificando pessoa, coisa ou atividade.

Não obstante, ambos os termos têm sua etimologia em ativo, adicionados de diferentes sufixos que, consequentemente, os convertem em palavras de diferentes aplicações e que, ainda que uma seja relativa à outra, conforme definição apresentada, não são consideradas sinônimos. 
ativo. adjetivo. 1.que exerce ação; que age. (...) 2.que tem a faculdade de agir. (...) 3.que atua de modo rápido, dinâmico; ágil, diligente, vivo. (...) 4.que participa ou influencia; atuante, participante. (...) 8.FILOSOFIA que possui a faculdade de agir livremente; não sujeito ao arbítrio de força estranha ou externa. (...) Origem. $\odot$ ETIM lat. actīvus, a, um 'ativo, que age, que tem significação ativa' (ATIVO, 2021)

Deste modo, com base no aspecto semântico, é possível apontar que o termo ativismo tem significados em diferentes áreas e que, nestas, identifica campos abrangentes de estudo e produção. Seu sufixo -ismo, por sua vez, aponta para a coletividade, indicando que sua adição é utilizada para a identificação de grupos. O termo ativista, por sua vez, tem como primeira definição que é "relativo a ativismo". Além disso, tanto os demais sentidos apresentados da palavra, quanto com relação ao uso do sufixo -ista, são aplicáveis à designação de sujeitos que atuam em alguma causa ou praticam alguma atividade.

Neste sentido, o uso do termo design ativista pode sugerir uma responsabilidade bastante individual, atribuída ao praticante, neste caso, o designer. Enquanto o termo design ativismo evoca práticas comuns de um grupo direcionado à uma área de atuação e campo de conhecimento.

Aqui, retomo os resultados da RBS com foco nos retornos em português, apresentando quantitativo por tipo de documento (tabela 1) e quantitativos dos achados por termo e ano de publicação (tabela 2).

\begin{tabular}{|l|l|}
\hline Tipo de documento acadêmico & $\mathbf{N}^{\mathbf{0}}$ de resultados \\
\hline Anais de eventos & 8 \\
\hline Capítulo de livro & 1 \\
\hline Livro & 1 \\
\hline Periódico & 8 \\
\hline TCC & 2 \\
\hline Dissertação de mestrado & 16 \\
\hline Tese de doutorado & 5 \\
\hline
\end{tabular}

Tabela 1: Tipo e quantitativo de documentos acadêmicos em português encontrados na RBS Fonte: a autora (2021)

\begin{tabular}{|l|l|l|l|l|l|l|l|l|}
\hline Tipo de documento acadêmico & $\mathbf{2 0 1 2}$ & $\mathbf{2 0 1 3}$ & $\mathbf{2 0 1 6}$ & $\mathbf{2 0 1 7}$ & $\mathbf{2 0 1 8}$ & $\mathbf{2 0 1 9}$ & $\mathbf{2 0 2 0}$ & $\mathbf{2 0 2 1}$ \\
\hline "design ativismo" & & & 2 & 1 & 3 & 2 & 1 & \\
\hline "design ativista" & 1 & 1 & 2 & 1 & 2 & 7 & 12 & 3 \\
\hline "design ativismo" e "design ativista" & & & & & & & 3 & \\
\hline
\end{tabular}

Tabela 2: Quantitativo dos documentos acadêmicos em português encontrados na RBS por termo por ano Fonte: a autora (2021)

A partir deste panorama, baseado na análise dos achados em português e da leitura dos resumos, foram selecionados 11 materiais para aprofundamento (1 trabalho de conclusão de curso de graduação, 3 artigos de eventos, 3 dissertações de mestrado, 2 artigos em periódicos, e 2 teses de doutorado), a partir dos quais foi possível observar três principais aspectos que a serem discutidos na sequência.

O primeiro aspecto vem da análise geral e diz respeito a indícios de que o uso mais frequente do termo design ativista em português, em especial no Brasil, esteja relacionado à criação do coletivo 'Design Ativista', que teve início em junho de 2018, com o objetivo de unir profissionais da área criativa (designers, artistas, ilustradores etc.) para o desenvolvimento de materiais de cunho político com foco nas redes sociais e nas manifestações de rua. Até o ano de 2018, dentre as publicações existentes em português, localizadas pela RBS, o retorno das buscas com os termos 'design ativismo' e 'design ativista' era bastante parecido, 6 e 7 respectivamente. Esses indícios são reforçados ao identificar que, após 2018 passa a haver mais textos acadêmicos utilizando o 
termo 'design ativista' (22) em comparação a 'design ativismo' (3) ou, ainda, que utilizam os 2 termos (3).

A existência de tal grupo já era conhecido pela autora, mas apareceu também como resultado da RBS, em dois artigos de evento e um trabalho de conclusão de curso. Em um dos artigos de evento retornou com o uso do termo "design ativista" e os outros dois documentos com o uso dos dois termos. Respectivamente, Queiroz e Villas-Boas (2020) apresentam e descrevem o coletivo como exemplo, uma vez que o artigo trata do campo do design visual e sua postura historicamente crítica. Já Magro Junior, Moura e Guimarães (2020) versam sobre o design contemporâneo e suas práticas, posicionando o design ativismo dentro do escopo destas e apresentando a conta 'Design Ativista' (@ designativista) no Instagram como estudo de caso. Aparece também no TCC de Queiroz (2020) na seção sobre "Design e ativismo e design como resistência" onde discute o papel do designer como agente social.

O segundo aspecto refere-se ao sentido dado ou utilizado pelos autores e pelas autoras que utilizaram os diferentes termos. Dentre os treze materiais selecionados para aprofundamento, dois resultados utilizaram os dois termos, cinco empregaram o termo 'design ativismo' e seis usaram 'design ativista'.

Conforme mencionado acima, os autores Magro Junior, Moura e Guimarães (2020) e Queiroz, (2020), utilizam ambos os termos 'design ativismo' e 'design ativista' e apresentam o design ativismo como prática cidadã e o designer como agente social, e trazem, respectivamente, $o$ coletivo 'Design Ativista' descrito como estudo de caso e como exemplo de prática deste campo de atuação. Já Portinari e Nogueira (2016) e Nogueira (2018) tratam em seus artigos aspectos do que chamam design político e, devido às características políticas apresentadas por Thorpe (2012) como 'design ativismo', os autores utilizaram este termo para falar sobre uma forma de atuação política do design, ainda que suas argumentações sejam críticas a esta nomenclatura. Hernandes (2018) e Montuori (2018) adotam 'design ativismo' como tradução literal para 'design activism' apoiadas nas definições de Fuad-Luke (2009), Thorpe (2012), Markussen (2013) e Julier (2013).

Para os seis trabalhos com o termo 'design ativista', percebeu-se que, em quatro deles, Albuquerque (2018), Prado (2019), Batista e Meyer (2020) e Lopes (2020) os autores o utilizaram como tradução ao termo em inglês design activism, bem como o entendimento do significado adotado está alinhado às definições de Fuad-Luke (2009) e Thorpe (2012), citados nestes trabalhos. Albuquerque (2018), ainda que não mencione os dois referidos autores, baseia seu entendimento do termo na definição apresentada no evento Design Activism and Social Change ocorrido em Barcelona em 2011. Já no sexto achado com o uso deste termo, os autores Queiroz e Villas-Boas (2020) o utilizam para descrever o grupo 'Design Ativista', como apontado acima.

Assim, a partir deste panorama, de análise dos termos, suas definições léxicas e a literatura existente, tendo em vista o caráter coletivo deste campo de atuação do design e buscando uma melhor correlação do uso dos termos em diferentes idiomas, propõe-se como recomendação a adoção, em português, do termo design ativismo. 


\section{Considerações finais}

O designer dá forma às ideias de maneira tangível e, com isso, molda também expressões de ser e se comportar das pessoas, evidenciando aspectos econômicos, sociais e culturais. Pode, então, consciente desta capacidade, trabalhar para a manutenção dos valores vigentes e do status quo ou atuar na criação de contra narrativas, com foco na promoção de efetivas mudanças e transformações na sociedade.

Enquanto campo do conhecimento, já há algumas décadas, existe tensionamento quanto ao seu papel como solucionador de problemas reais ou inventados apenas para fins de lucro da iniciativa privada. Desta tensão, e da emergência na promoção de mudanças significativas do ponto de vista social, ambiental e econômico na sociedade, surgiram abordagens relacionadas à sustentabilidade, inovação social entre outras. No entanto, face à pressão econômica, motor do sistema capitalista vigente, aspectos sociais e ambientais continuam sendo seus próprios custos, cujos impactos recaem sempre sobre as populações mais vulneráveis. Neste cenário, emergem as práticas ativistas do design, buscando superar tais dificuldades, questionando e confrontando o sistema, propondo contra narrativas e abrindo espaço para estratégias de participação política da sociedade nas esferas públicas de decisão.

A característica recente desta área de atuação do design e as diferenças de terminologia utilizadas nas publicações existentes levou a esta investigação, que buscou por meio da análise da literatura canônica do design e de uma revisão bibliográfica sistemática recomendar a utilização do termo design ativismo para publicações em português. Isto se deve, principalmente, a três aspectos, o primeiro se refere à análise das palavras, a partir da qual foi percebido que o sufixo ismo aponta para a coletividade. O segundo aspecto é relativo ao fato de que design ativismo é a tradução literal do termo corrente mais utilizado em inglês, e a terceira, a de que nos trabalhos em português, que utilizaram o outro termo, o fizeram, em boa parte, como se fosse a tradução, já que os significados adotados bebem majoritariamente das fontes de base do design activism, em inglês.

A reflexão trazida neste artigo levou também a questionamentos, que coloco aqui como encaminhamentos para trabalhos futuros, sobre possíveis paralelos ou até mesmo contrapontos entre o design ativismo e o design político, caracterizado por Portinari e Nogueira (2016) e Nogueira (2018), como o campo do design que atua na criação de espaços de contestação.

\section{Referências}

ALBUQUERQUE, Elisabete Maria de. Design gráfico em tempos de ativismo. Dissertação (Mestrado em Design). Universidade Federal de Pernambuco. Recife, 2018.

ATIVISMO. In: Oxford Languages online. London: Oxford University Press, 2021.

ATIVISTA. In: Oxford Languages online. London: Oxford University Press, 2021.

ATIVO. In: Oxford Languages online. London: Oxford University Press, 2021.

BATISTA, Marcelo Vianna; MEYER, Guilherme Englert Corrêa. A emergência da diplomacia no ativismo a partir de uma prática experimental. In: SCALETSKY, Celso Carnos; MACCAGNAN, Ana Maria Copetti (coord.). Design Culture Symposium: scenarios, 
speculation and strategies. São Leopoldo: Universidade do Vale do Rio dos Sinos, Programa de Pós-Graduação em Design. p.81-90. 2020.

BONSIEPE, Gui. A Tecnologia da Tecnologia. São Paulo: Edgard Blucher, 1983.

BUCHANAN, Richard. Wicked Problems in Design Thinking. In: Design Issues, Vol. 8, n. 2, p. 5-21, 1992.

CROSS, Nigel. Designerly ways of knowing. Design Studies, Vol. 3, n. 4, p. 221-227, 1982.

DENIS, Rafael Cardoso. Uma Introdução à História do Design. São Paulo: Edgard Blucher Ltda, 2000.

DORMER, Peter. The Meanings of Modern Design: Towards the twenty-first century. London: Thames e Hudson Ltda., 1990.

DRESCH, Aline; LACERDA, Daniel Pacheco; ANTUNER JR., José Antonio Valle. Design Science Research: Método de Pesquisa para Avanço da Ciência e Tecnologia. Porto Alegre: Bookman, 2015.

FRIEDMAN, Ken. Creating design knowledge: from research into practice. In: IDATER 2000 conference. Loughborough: Loughborough University, 2000. p. 5-32.

FORTY, Adrian. Objetos de desejo: design e sociedade desde 1750. Soares, Pedro Maia (tradução). São Paulo: Cosac Naify, 2007.

FUAD-LUKE. Alastair. Design activism: beautiful strangeness for a sustainable world. Sterling: Earthscan, 2009.

HAUFFE, Thomas. Design: a concise history. London: Laurence King, 1998.

HERNANDES, Maria Cristina Ibarra. Entrelaçando design com antropologia: engajamentos com um coletivo de moradores do bairro de Santa Teresa no Rio de Janeiro. Tese (Doutorado em Design). Universidade do Estado do Rio de Janeiro. Rio de Janeiro, 2018.

HESKETT, John. Desenho Industrial. Rio de Janeiro: José Olympio, 1997.

-ISMO. In: Oxford Languages online. London: Oxford University Press, 2021.

-ISTA. In: Oxford Languages online. London: Oxford University Press, 2021.

JULIER, Guy. From Design Culture to Design Activism. In: Design and Culture, Vol. 5, n. 2, p. 215-236, 2013.

LEFEBVRE, Henri. Espaço e Política: O direito à cidade II. 2. Edição. Belo Horizonte: UFMG, 2016.

LÖBACH, Bernd. Design Industrial: bases para a configuração dos produtos industriais. São Paulo: Edgar Blücher, 2001.

LOPES. Pedro Bicá Viseu. Os desafios do design: design e metamodernismo. Dissertação (Mestrado em Práticas Tipográficas e Editoriais Contemporâneas). Universidade de Lisboa. Lisboa, 2020.

MAGRO JUNIOR, José Carlos; MOURA, Mônica Cristina; GUIMARÃES, Márcio James Soares. Design Ativismo como Prática Cidadã Contemporânea. Anais do Colóquio Internacional de Design, 2020.

MANZINI, Ezio. Design para a inovação social e sustentabilidade: comunidades criativas, organizações colaborativas e novas redes projetuais. Rio de Janeiro: E-papers, 2008.

MARGOLIN, Victor; MARGOLIN, Sylvia. A "Social Model" of Design: Issues of Practice and Research. In: Design Issues, Vol. 18, No. 4, p. 24-30, 2002.

MARKUSSEN, Thomas. The Disruptive Aesthetics of Design Activism: Enacting Design Between Art and Politics. In: Design Issues, Vol. 29, n. 1, p. 38-50, 2013. 
MONTUORI, Bruna Ferreira. Design, favela e ativismos: experiências e aprendizados com a Redes da Maré no Rio de Janeiro. Dissertação (Mestrado em Design e Arquitetura). Faculdade de Arquitetura e Urbanismo, Universidade de São Paulo. São Paulo, 2018.

MUNARI, Bruno. Das coisas nascem coisas. São Paulo: Martins Fontes, 2015.

NOGUEIRA, Pedro Caetano Eboli. Notas sobre uma política da estética voltada para o design. Educação Gráfica. Bauru, v. 22, n. 1, p. 6 - 17, 2018.

PAPANEK, Victor. Design for the Real World: Human Ecology and Social Change. New York: Bantam Books, 1973.

PORTINARI, Denise Berruezo; NOGUEIRA, Pedro Caetano Eboli. Por um design político. Estudos em Design. Rio de Janeiro: v. 24, n. 3, p. 32 - 46, 2016.

PRADO, Gheysa Caroline. Modelo para promoção da mobilidade urbana ativa por bicicleta: uma abordagem do design de serviços para o comportamento sustentável. Tese (Doutorado em Design). Universidade Federal do Paraná. Curitiba, 2019.

RESNICK, Elisabeth. The Social Design Reader. London: Bloomsbury, 2019.

RITTEL, Horst. W. J.; WEBBER, Melvin M. Dilemnas in a general theory of planning. In: Policy Sciences, v. 4, p. 155-169, 1973.

SIMON, Herbert Alexander. The Sciences of the Artificial. $3^{\text {rd }}$ Ed. London: MIT Press, 1996.

QUEIROZ, André Carvalho de Lima. Mídia Radical: Design como estratégia de ação coletiva no contexto da população em situação de rua da cidade de Fortaleza. Trabalho de Conclusão de Curso (Bacharelado em Design). Universidade Federal do Ceará. Fortaleza, 2020.

QUEIROZ, André Vieira; VILLAS-BOAS, André. Design visual, hegemonia e ativismo. Anais do Colóquio Internacional de Design, 2020.

SUDJIC, Deyan. A linguagem das coisas. Rio de Janeiro: Intrínseca, 2010.

THORPE, Ann. Architecture and Design versus Consumerism: How design activism confronts growth. New York: Earthscan, 2012.

WDO - World Design Assembly. Definition of Industrial Design. In: 29th General Assembly in Gwangju (South Korea), 2015. Disponível em: <https://wdo.org/about/definition/>. Acesso em: 10 mai. 2021.

\section{Sobre a autora}

\section{Gheysa Caroline Prado}

É doutora em Design pela Universidade Federal do Paraná (2019) e docente no curso de Design de Produto e do Programa de Pós-graduação em Design da Universidade Federal do Paraná. Vinculada aos grupos de pesquisa de Teoria, história e crítica do design e atividades projetuais (UFPR), Design Colaborativo e Cocriação (UFPR) e Gestão do Design (UFPR). Seus interesses de pesquisa são design ativismo, inovação social, design e cultura material, e design e cidades com foco na mobilidade urbana ativa.

https://orcid.org/0000-0002-4405-1702 